\title{
Predictive use of routine 24-hour electrocardiography in suspected Adams-Stokes syndrome Comparison with cardiac rhythm during symptoms
}

\author{
NILS-JOHAN ABDON, BENGT W JOHANSSON, JAN LESSEM \\ From the Section of Cardiology, Medical Department, Malmö General Hospital, Malmö, Sweden
}

SUMMARY Using strictly defined criteria of significant arrhythmias, long term electrocardiographic recording has been evaluated for confirmation of arrhythmias as the cause of cerebral symptoms in 81 patients with suspected Adams-Stokes syndrome.

Extension of long term electrocardiographic recording for more than 24 hours gives marginal additional information at a high cost. Among 43 patients monitored until symptoms appeared, non cardiogenic causes were confirmed in 20 of 22 patients because the recording showed normal rhythm during symptoms. Fifteen of 21 patients with a significant arrhythmia during an asymptomatic 24 hour recording later had the same arrhythmia during symptoms.

Of 38 patients who failed to develop symptoms, 21 had a significant arrhythmia detectable within 24 hours and 23 when 48 hours of recording were analysed.

Long term electrocardiographic recording has disclosed that 20 to $75 \%$ of patients with suspected Adams-Stokes syndrome have serious arrhythmias known to or presumed to correlate with cerebral symptoms. ${ }^{1-22}$ The varying rates of positive findings might be explained by differences in patient selection. Variations in duration of long term electrocardiographic recording and criteria for serious arrhythmias should also be considered. Lopes et al. ${ }^{23}$ observed a moderate increase in ectopic beats while Jonas et al. ${ }^{13}$ observed an increase in pertinent arrhythmias from 14 to $23 \%$ as long term electrocardiographic recording was extended from 12 to 24 hours. Kennedy et al., ${ }^{24}$ however, found that most instances of ventricular arrhythmias were correctly graded within 24 hours. Less is known about the increased detection of bradycardias as long term electrocardiographic recording is prolonged, but Tzivoni and Stern ${ }^{25}$ reported that most cases with bradycardias severe enough to require pacemaker treatment were detected within 24 hours. Prolongation of long term electrocardiographic recording until symptoms appear may establish a temporal relation between arrhythmias and symptoms or it may rule out the AdamsStokes syndrome by recording a normal cardiac rhythm during symptoms.
The main purpose of the present study is to compare the cardiac rhythm during symptoms with the arrhythmias detected during a 24 hour long term electrocardiographic recording using strict criteria for significant arrhythmias. In patients who failed to develop symptoms we determined the increase of serious arrhythmias detectable by prolonging long term electrocardiographic recording from 24 to 48 hours.

\section{Patients and methods}

Each year about 1300 patients are referred to the Section of Cardiology because of suspected AdamsStokes syndrome. Regardless of previous electrocardiographic findings all of them are subjected to a routine 24 hour electrocardiographic recording.

This study included 81 patients aged 15 to 86 years (mean 61 \pm SD16) suspected of having Adams-Stokes syndrome. During a four month period they were all selected because of weekly or more frequent attacks of syncope $(n=17)$, dizziness including presyncope $(n=45)$, or both $(n=19)$. All patients had consented to wear an electrocardiographic tape recorder until symptoms had occurred and were expected to keep a diary noting the time of symptoms. Patients with recent changes in their cardiac medication were excluded. An examination was performed before the study in order to detect possible non-cardiac causes of 
symptoms. All patients participated for at least 48 hours but 38 patients terminated recording before symptoms because of subjective discomfort.

A previous myocardial infarction was suffered by eight patients while seven others were treated with digitalis and/or diuretics because of heart failure. Seventy-three patients were in sinus rhythm and had no pertinent arrhythmias detectable in their routine 12 lead electrocardiograms. One patient had atrial fibrillation with appropriate ventricular rates, while six had sinus rhythm plus ectopics or episodes of tachycardias, and one had a bradycardia of 50 beats per minute (bpm) or less (sinus bradycardia).

\section{LONG TERM ELECTROCARDIOGRAPHIC RECORDING}

Long term electrocardiographic recording was performed using portable electrocardiographic tape recorders type SRA/HRB-3 (Helcomed Norden/ Hellige). The patients revisited the Section of Cardiology every second day for a technical check-up.

\section{SCREENING OF ELECTROCARDIOGRAPHIC TAPES}

The tapes were screened by one of two automatic units. One unit writes out all rhythms corresponding to rates faster than 120 or slower than $40 \mathrm{bpm}$, detected by a single $R R$ interval, as a one-channel electrocardiogram on a paper strip. Write-out from the other unit is triggered by an increase or decrease of the cycle length of $30 \%$ or more of the average from the last minute of recording. In addition, both units write out every 10th ventricular extrasystole occurring within one minute of recording as detected by QRS configuration criteria. All electrocardiographic write-outs were screened by a specialised laboratory technician and one of the authors (N-J A).

\section{CLASSIFICATION OF ARRHYTHMIAS}

Arrhythmias known or presumed to correlate with cerebral symptoms were termed significant. Minor arrhythmias expected to occur in asymptomatic elderly subjects were classified as insignificant and omitted from this presentation.

The criteria of significant arrhythmias were based on the findings made when 103 elderly subjects (mean age $71 \pm 11$ years) selected at random from the general population were examined by 24 hour long term electrocardiographic recording using the same equipment and screening limits. ${ }^{26}$ The following arrhythmias were termed significant: frequent ventricular extrasystoles whenever one was followed by a second ventricular extrasystole within no more than five beats and this second extrasystole was followed by a third extrasystole within no more than five complexes, potentially dangerous extrasystoles ${ }^{27}$ being observed separately; atrial tachycardias at a rate of $\geqslant 120 / \mathrm{min}$ and duration $>8 \mathrm{~s}$. The sick sinus syndrome was diagnosed according to one or more of the following criteria: (1) Sinus bradyarrhythmias $\leqslant 50 \mathrm{bpm}$ and with a variation in consecutive PP intervals of $\geqslant 20 \%$; (2) regular sinus bradycardia $\leqslant 45 \mathrm{bpm}$ when awake; (3) sinoatrial block; and (4) sinus arrests of $\geqslant 1.5 \mathrm{~s}$. The lowest rates were calculated from a sequence of three or more beats of the basic rhythm. Patients with the sick sinus syndrome and additional episodes of atrial tachyarrhythmias were considered to have the bradycardia-tachycardia syndrome.

Second and third degree atrioventricular block was always significant. In atrial fibrillation third degree block was designated if the ventricular rate, as calculated from three or more consecutive beats, was $\leqslant 40$ bpm or 41 to $50 \mathrm{bpm}$ with a QRS morphology different from that of conducted beats.

\section{Results}

The 81 participating patients were divided into two groups. One group consisted of 43 patients who tolerated long term electrocardiographic recording until symptoms appeared and one group of 38 patients terminating long term electrocardiographic recording at varying times $\geqslant 48$ hours but before symptoms. Examination continued for two to 21 days (mean four).

\section{PATIENTS WITH SYMPTOMS DURING LONG TERM} ELECTROCARDIOGRAPHIC RECORDING

Among the 43 patients with symptoms 28 had syncope or dizzy spells. In 15 patients the symptoms during recording were cardiac but of ten connected with a sensation of pending collapse or associated with the onset of typical cerebral symptoms.

The arrhythmia diagnoses during the 24 hour periods and the number of patients with symptoms are shown in Table 1 together with patients with a normal rhythm during symptoms.

During the asymptomatic period 22 patients had no significant arrhythmias. A non-cardiac cause of their symptoms could be confirmed in $20(91 \%)$ patients who had no significant arrhythmia during the entire 24 hour period during which symptoms occurred. Two patients lacking significant arrhythmias during the initial 24 hour period had atrial tachyarrhythmias when symptoms later developed (Table 1).

Twenty-one patients had significant arrhythmias 6 suggesting a cardiac origin during the asymptomatic period. When symptoms appeared it was confirmed that the same arrhythmia previously recorded was related to symptoms in 15 (71\%) of them. Furthermore, one patient with atrial tachyarrhythmias both initially and during symptoms had episodes of sinus bradycardia unrelated to symptoms during the same 
Table 1 Patients examined by long term electrocardiographic recording until appearance of symptoms: Comparison of arrhythmia diagnosis from routine 24 hour recording with recordings when symptoms occurred

\begin{tabular}{|c|c|c|c|c|}
\hline \multirow[t]{2}{*}{$\begin{array}{l}\text { Arrhythmia } \\
\text { diagnosis }\end{array}$} & \multirow{2}{*}{$\begin{array}{l}\text { Asymptomatic } \\
\text { (routine) } 24 \\
\text { hour period }\end{array}$} & \multicolumn{2}{|c|}{$\begin{array}{l}\text { Symptomatic } \\
24 \text { hour period }\end{array}$} & \multirow{2}{*}{$\begin{array}{l}\text { Patients with } \\
\text { normal rhythm } \\
\text { symptoms }\end{array}$} \\
\hline & & $\begin{array}{l}\text { Same } \\
\text { arrhythmia }\end{array}$ & $\begin{array}{l}\text { Other } \\
\text { arrhythmia }\end{array}$ & \\
\hline $\begin{array}{l}\text { Not significant } \\
\text { Atrial tachyarrhythmias }\end{array}$ & $\begin{array}{r}22 \\
7\end{array}$ & $\begin{array}{r}20 \\
6\end{array}$ & $\begin{array}{l}2 \text { (atrial tachyarrh) } \\
1 \text { (SSS) }\end{array}$ & $\begin{array}{r}20 \\
2\end{array}$ \\
\hline \multicolumn{5}{|l|}{ Sick sinus syndrome: } \\
\hline Brady-tachy & 6 & 6 & 0 & 1 \\
\hline Brady only & 1 & 1 & 0 & $i$ \\
\hline Atrioventricular block, third degree & 1 & 1 & 0 & 0 \\
\hline Frequent ventricular extrasystoles & 2 & 2 & 0 & 1 \\
\hline Couplets ventricular extrasystoles/ventricular tachycardia & 4 & 4 & 0 & 1 \\
\hline
\end{tabular}

24 hour period in which symptoms occurred. This allowed the correct diagnosis of a bradycardiatachycardia syndrome.

In six of the 21 patients who had significant arrhythmias during the initial period, symptoms did not occur simultaneously with the arrhythmias. One of these patients, however, later reported the disappearance of cerebral symptoms after pacemaker implantation and three reported the disappearance of symptoms on antiarrhythmic medication.

In 13 of the 15 patients with simultaneous arrhythmias both initially and during later symptoms the arrhythmias observed in connection with symptoms were of the same type and severity as those previously observed during the asymptomatic period. Notable aggravations of pre-existing arrhythmias were observed in only two cases as they fainted: one with couplets of ventricular extrasystoles developed ventricular tachycardia and one with third degree atrioventricular block had an asystole of 21 seconds.

A new type of additional significant arrhythmia was discovered during the period in which symptoms occurred in three patients. They had frequent ventricular extrasystoles temporarily unrelated to symptoms.

Use of less strict criteria for significant arrhythmia Among the 20 patients with no significant arrhythmia at any time during the recording (including during symptoms-Table 1) eight had moderately frequent ectopic beats, two had atrial tachyarrhythmias lasting for a few seconds unrelated to symptoms, and four had a perfectly regular sinus bradycardia at the time of sleep. Among six patients with a bradycardia related to symptoms, three had moderately frequent ectopic beats and two had tachyarrhythmias lasting for a few seconds without relation to symptoms.

\section{PATIENTS WITHOUT SYMPTOMS DURING LONG} TERM ELECTROCARDIOGRAPHIC RECORDING Thirty-eight patients had no symptoms during monitoring. Nineteen had no significant arrhythmias during the intitial 24 hour period, $18(95 \%)$ of them remaining free from significant arrhythmias when long term electrocardiographic recording was extended to 48 hours. The one patient discovered by prolonging the period of recording had atrial tachyarrhythmias, and the remaining five patients with atrial tachyarrhythmias were discovered within 24 hours of long term electrocardiographic recording. All eight patients with the sick sinus syndrome, all three with second or third degree atrioventricular block, and both patients with ventricular arrhythmia were detected during the first 24 hours of recording. Three patients, however, with significant arrhythmias during the first 24 hours had the additional finding of ventricular arrhythmia as long term electrocardiographic recording was extended from 24 to 48 hours (Table 2).

\section{Discussion}

The clinical management of patients with cerebral symptoms and episodic cardiac arrhythmia has of necessity been empirical unless a temporal relation between arrhythmias and symptoms could be established. The present study investigated the adequacy of a routine 24 hour electrocardiographic recording using strict criteria for significant arrhythmias by comparing the arrhythmias initially present with the cardiac rhythm during later symptoms.

ARRHYTHMIAS DURING INITIAL (ROUTINE) 24 HOURS VERSUS RECORDINGS DURING SYMPTOMS

Among the 43 patients with electrocardiographic recordings until symptoms appeared, the asymptomatic periods included no significant arrhythmia in 22 . By recording the cardiac rhythm during symptoms a non-cardiac cause of symptoms could be confirmed in 20 . Thus, with the presently used classification of significant arrhythmias a negative routine 24 hour long term electrocardiographic recording gave a $91 \%$ prediction that the rhythm during symptoms would be normal. 
Table 2 Patients without symptoms during monitoring: comparison of arrhythmia diagnosis (significant arrhythmias only) present durng initial 24 hour period with arrhythmia diagnoses when second 24 hour period included

\begin{tabular}{|c|c|c|c|c|}
\hline \multirow[t]{2}{*}{$\begin{array}{l}\text { Arrhythmia } \\
\text { diagnosis }\end{array}$} & \multirow[t]{2}{*}{$\begin{array}{l}\text { From initial } \\
24 \text { hour period }\end{array}$} & \multicolumn{2}{|c|}{$\begin{array}{l}\text { With second } \\
24 \text { hour period } \\
\text { included }\end{array}$} & \multirow[t]{2}{*}{$\begin{array}{l}\text { New additional } \\
\text { significant } \\
\text { arrhythmia }\end{array}$} \\
\hline & & Same & Other & \\
\hline No significant arrhythmia & 19 & 18 & 1 (atrial tachy) & \\
\hline Atrial tachyarrhythmias & 5 & 5 & 0 & $\begin{array}{l}1 \text { ventricular } \\
\text { extrasystoles }\end{array}$ \\
\hline \multicolumn{5}{|l|}{ Sick sinus syndrome } \\
\hline Brady-tachy & 4 & 4 & 0 & $\begin{array}{l}1 \text { ventricular } \\
\text { extrasystoles }\end{array}$ \\
\hline Brady only & 4 & 4 & 0 & \multirow{4}{*}{$\begin{array}{l}1 \text { ventricular } \\
\text { extrasystoles }\end{array}$} \\
\hline Atrioventricular dissociation & 1 & 1 & 0 & \\
\hline Atrioventricular block second/third degree & 3 & 3 & 0 & \\
\hline Frequent ventricular extrasystoles, couplets & 2 & 2 & 0 & \\
\hline
\end{tabular}

When the 24 hour recording suggested that arrhythmia was the cause of symptoms this was confirmed in 15 of 21 patients ( $71 \%$ ) by recodring the same arrhythmia during symptons. Four of six patients, however, with significant arrhythmias not coinciding with symptoms improved on antiarrhythmic therapy. This improvement may have been spontaneous and the cause was not investigated further. Hence a routine 24 hour recording with significant arrhythmia was either confirmed or, using the terminology of Ward et al., ${ }^{22}$ clinically useful in $90 \%$ of the cases.

The managment of patients with significant arrhythmias is frequently based on the presumption that the arrhythmias documented are the antecedents of more serious arrhythmias. Among our 15 patients with simultaneous arrhythmia and symptoms this was only observed in two. The remaining 13 patients showed a varying response to the same arrhythmia.

Three previous reports ${ }^{161922}$ have demonstrated temporal relations between arrhythmias and cerebral symptoms in less than $10 \%$ of patients, while other reports showed from 13 to $76 \%$, but a considerable number of patients have no significant arrhythmia at any time of the recording including during symptoms. There is little doubt that the former deserves treatment for arrhythmias and that a non-cardiac cause should be sought among the latter. More difficult is how to treat patients with significant arrhythmias unrelated to time of symptoms. It is worth while noting that four of six such patients in this series may later have responded to treatment. Conversely in another series 35 out of $44(80 \%)$ patients without treatment for significant arrhythmias had persisting cerebral symptoms. ${ }^{28}$

There are several possible explanations for the lack of correlation between arrhythmias and symptoms in patients who may really have the Adams-Stokes syndrome. As pointed out before ${ }^{13}$ temporary impairment of memory is part of the disorder. There may be failure to report symptoms, ${ }^{18}$ the incorrect timing of events, or difficulties in obtaining adequate diaries. 5132022

A major reason for lack of correlation between arrhythmias and symptoms may be a broader definition of significant arrhythmias. The report of Clark et al. ${ }^{19}$ with a low incidence of patients with temporal relation between symptoms and arrhythmia may be illustrative of this, since the same group also provided a detailed report of the application of their criteria for significant arrhythmias in an elderly asymptomatic population of 13 subjects. ${ }^{29}$ No less than 10 of these 13 subjects had "significant" arrhythmias. With the criteria currently used only nine of 77 asymptomatic elderly subjects ${ }^{26}$ had significant arrhythmias. Correspondingly, a high rate of positive correlation with later symptoms was obtained in this series.

\section{PATIENTS WITHOUT SYMPTOMS DURING RECORDING}

Eighteen of the 19 patients with an initial 24 hour recording remained free from significant arrhythmias as long term electrocardiographic recording was extended from 24 to 48 hours. Among the 19 patients with significant arrhythmias during the initial 24 hour period three had an additional type of significant arrhythmia during the second period; the arrhythmia was ventricular in all three. Thus, the originally detected types of significant arrhythmia were confirmed as the only ones in $84 \%$ of those having significant arrhythmias during the initial 24 hour period.

Remarkably little is known about the increased detection of all types of significant arrhythmias attainable by prolongation of long term electrocardiographic recording. Lopes et al. ${ }^{23}$ and Jonas et al. ${ }^{13}$ reported that extension of long term recording from 12 to 24 hours resulted in considerable increases in ventricular or pertinent arrhythmias, respectively. 
Kennedy et al. ${ }^{24}$ found that the overwhelming majority of ventricular arrhythmias were detected within 24 hours when a comparison with additional days of recording were made. Among the entire series of 81 patients we noted that 19 of 20 cases with bradyarrhythmias were detected within 24 hours, but three of 14 patients with atrial tachyarrhythmias required prolonged monitoring for their detection.

\section{COMPARISON WITH ASYMPTOMATIC}

\section{POPULATIONS}

In patients not experiencing symptoms during long term electrocardiographic recording the evaluation may be assisted by comparison with findings reported from asymptomatic populations.

Several investigations ${ }^{30-34}$ have shown that almost every young, middle-aged, or elderly individual will have some type of cardiac arrhythmia when the electrocardiographic recording is continued for a sufficient time. A further analysis, however, discloses that sinus bradycardia is extremely common in young subjects, ${ }^{31}{ }^{33}$ while it is rare among elderly subjects. ${ }^{35}$

Seemingly in contrast with these more or less epidemiological investigations some clinically active centres have found that serious episodic arrhythmias are rare among selected normal elderly subjects. 143536 This centre reported the findings when 103 elderly subjects selected at random from the general population were examined by 24 hour long term electrocardiographic recording. ${ }^{26}$ Twenty-six of them admitted syncope and/or dizziness while 77 did not. Twelve of the 26 symptomatic and nine of the 77 asymptomatic subjects had significant arrhythmias according to the classification currently used $(p<0.001)$. This may explain why so many of our patients had coinciding significant arrhythmias and symptoms. The use of strict criteria derived from the population study may also explain the high degree of prediction achieved from an asymptomatic 24 hour recording.

\section{ECONOMIC ASPECTS}

The costs involved in extended recording were impressive when related to the additional information obtained. Each new case of significant arrhythmia cost 5.7 times that of a significant arrhythmia discovered during routine recordings. Facilities for long term electrocardiographic recording are limited and we have chosen to screen a large group of patients with possible Adams-Stokes attacks ${ }^{37}$ with a 24 hour electrocardiogram rather than to concentrate resources on a small group of patients.

\section{Conclusions}

We conclude that the routine 24 hour long term elec- trocardiographic recording will be sufficient to detect most patients with Adams-Stokes syndrome. When strictly defined criteria for significant arrhythmias are applied, the need for recording until symptoms occur will be reduced. Prolonged monitoring should be used principally in patients with problems of differential diagnosis or when there is strong evidence of the Adams-Stokes syndrome despite an initial negative recording. Provided that long term electrocardiographic recordings are interpreted with an open mind, the routine application of a 24 hour period should be acceptable, with the understanding that prolonged monitoring may be needed exceptionally.

\section{References}

1 Corday E, Bazika V, Lang TW, Pappelbaum S, Gold H, Bernstein H. Detection of phantom arrhythmias and evanescent electrocardiographic abnormalities. $\mathcal{F A M A}$ 1965; 193: 417-21.

2 Stern S, Ben-Shachar G, Tzivoni D, Braun K. Detection of transient arrhythmias by continuous long-term recording of electrocardiograms of active subjects. Isr $\mathcal{F} \mathrm{Med} \mathrm{Sci}$ 1979; 6: 103-12.

3 Walter PF, Reid SD Jr, Wenger NK. Transient cerebral ischemia due to arrhythmia. Ann Intern Med 1970; 72: 471-4.

4 Bleifer SB, Bleifer DJ, Hansmann DR, Sheppard JJ, Karpman HL. Diagnosis of occult arrhythmias by Holter electrocardiography. Prog Cardiovasc Dis 1974; 16: 569-99.

5 Goldberg AD, Raftery EB, Cahsman PMM. Ambulatory electrocardiographic records in patients with transient cerebral attacks or palpitation. $\mathrm{Br}$ Med $\mathcal{F}$ 1975; iv: 56971.

6 Van Durme JP. Tachyarrhythmias and transient cerebral ischemic attacks. Am Heart $\mathcal{F}$ 1975; 89: 538-40.

7 Levin EB. Use of the Holter electrocardiographic monitor in the diagnosis of transient ischemic attacks. $\mathcal{F}$ Am Geriatr Soc 1976; 24: 516-21.

8 Lipski J, Cohen L, Espinoza J, Motro M, Dack S, Donoso E. Value of Holter monitoring in assessing cardiac arrhythmias in symptomatic patients. Am $\mathcal{F}$ Cardiol 1976; 37: 102-7.

9 McHenry LC Jr, Toole JF, Miller HS. Long term ECG monitoring in patients with cerebrovascular insufficiency. Stroke 1976; 7: 264-9.

10 Romero CA Jr. Holter monitoring in the diagnosis and management of cardiac rhythm disturbances. Med Clin North Am 1976; 60: 299-313.

11 Johansson BW. Long-term ECG in ambulatory clinical practice. Eur 7 Cardiol 1977; 5: 39-48.

12 Cadigan PJ, Williams DO. 24-hour ambulatory electrocardiographic monitoring on a regional basis. $\mathrm{Br} \mathrm{Med}$ f 1977; iii: 439-40.

13 Jonas S, Klein I, Dimant J. Importance of Holter monitoring in patients with periodic cerebral symptoms. Ann Neurol 1977; 1: 470-4.

14 McCarthy ST, Wollner L. Cardiac dysrhythmias: treatable cause of transient cerebral dysfunction in the elderly (letter). Lancet 1977; ii: 202-3. 
15 Swenson RD, Price JE, Fashinell TR, et al. High prevalence of cardiac dysrhythmias in the etiology of syncope and dizziness: documentation by ambulatory monitoring (abstract). Circulation 1977; 55-56; suppl 3: III-24.

16 Kennedy i. $\mathrm{T}$, Wheeler CJ, Poblete PF, Caralis DG. Evaluation of dizziness and syncope by 24-hour ambulatory electrocardiography (abstract). Am f Cardiol 1978; 41: 402.

17 Abdon N-J. Clinical considerations in the diagnosis of cerebral ischemia caused by episodic cardiac dysrhythmias. In: Busse E, ed. Cerebral manifestations of episodic cardiac dysrhythmias. Princeton: Excerpta Medica, 1979: 93-102.

18 Boudoulas H, Schaal SF, Lewis RP, Robinson JL. Superiority of 24 hour outpatient monitoring over multi-stage exercise testing for the evaluation of syncope. F Electrocardiol 1979; 12: 103-8.

19 Clark PI, Glasser SP, Spoto E Jr. Arrhythmias detected by ambulatory monitoring. Lack of correlation with symptoms of dizziness and syncope. Chest 1980; 77: 722-5.

20 Zeldis SM, Levine BJ, Michelson EL, Morganroth J. Cardiovascular complaints. Correlation with cardiac arrhythmias on 24-hour electrocardiographic monitoring. Chest 1980; 78: 456-62.

21 Shenhasa M, Curry PVL, Sowton E. The relationship between symptoms and arrhythmias during 24hour ECG recording. In: Stott FD, Raftery EB, Goulding L, eds. ISAM 1979. Proceedings of the third international symposium on ambulatory monitoring. London: Academic Press, 1980: $39-48$.

22 Ward DE, Camm AJ, Darby N. Diagnostic information from a national ambulatory monitoring (ECG) service. In: Stott FD, Raftery EB, Goulding L, eds. ISAM 1979. Proceedings of the third international symposium on ambulatory monitoring. London: Academic Press, 1980: 123-32.

23 Lopes MG, Runge P, Harrison DC, Schroeder JS. Comparison of 24 versus 12 hours of ambulatory ECG monitoring. Chest 1975; 67: 269-73.

24 Kennedy HL, Chandra V, Sayther KL, Caralis DG. Effectiveness of increasing hours of continuous ambulatory electrocardiography in detecting maximal ventricular ectopy. Am f Cardiol 1978; 42: 925-30.

25 Tzivoni D, Stern S. Pacemaker implantation based on ambulatory ECG monitoring in patients with cerebral symptoms. Chest 1975; 67: 274-8.
26 Abdon N-J. Frequency and distribution of long-term ECG-recorded cardiac arrhythmias in an elderly population, with special reference to neurological symptoms. Acta Med Scand 1981; 209: 175-83.

27 Lown B, Wolf M. Approaches to sudden death from coronary heart disease. Circulation 1971; 44: 130-42.

28 Abdon N-J. Long-term electrocardiographic recordings in suspected Adams-Stokes syndrome. Part Idiagnostic aspects. Acta Med Scand. Submitted for publication.

29 Glasser SP, Clark PI, Aplebaum HJ. Occurrence of frequent complex arrhythmias detected by ambulatory monitoring. Chest 1979; 75: 565-8.

30 Hinkle LE, Carver ST, Stevens $M$. The frequency of asymptomatic disturbances of cardiac rhythm and conduction in middle-aged men. Am 7 Cardiol 1969; 24: 629-50.

31 Engel UR, Burckhardt D. Häufigkeit und Art von Herzrhythmusstörungen sowie EKG-Veränderungen bei jugendlichen herzgesunden Probanden. Schweiz Med Wochenschr 1975; 105: 1467-9.

32 Clarke JM, Hamer J, Shelton JR, Taylor S, Venning GR. The rhythm of the normal human heart. Lance 1976; ii: $508-12$.

33 Brodsky M, Wu D, Denes P, Kanakis C, Rosen KM Arrhythmias documented by 24 hour continuous electrocardiographic monitoring in 50 male medical students without apparent heart disease. Am $\mathcal{F}$ Cardiol 1977; 39, $390-5$.

34 Adey H, Ballantyne DA, Bostock MI, et al. The prevalence of disturbances of cardiac rhythm in healthy New Zealand adults: a pilot study. NZ Med f 1978; 88: 433-5.

35 Camm AJ, Evans KE, Ward DE, Martin A. The rhythm of the heart in active elderly subjects. Am Heart $\mathcal{F} 1980$ 99: 598-603.

36 Raftery EB, Cashman PMM. Long-term recording of the electrocardiogram in a normal population. Postgrad Med f 1976; 52, suppl 7: 32-7.

37 Johansson BW. Symptoms suggesting cardiac arrhythmias. In: Chamberlain DA, Kulbertus H, Mogensen L, Schlepper M, eds. Cardiac arrhythmias in the active population. Prevalence, significance and management. Mölndal: AB Hässle, 1980; 12-5.

Requests for reprints to Dr Nils-Johan Abdon, Section of Cardiology, Medical Department, General Hospital, S-214, Malmö, Sweden. 